\title{
Comparative Evaluation of Different Sanitizers Against Listeria monocytogenes Biofilms on Major Food-Contact Surfaces
}

OPEN ACCESS

Edited by:

Viduranga Y. Waisundara, Australian College of Business and

Technology, Sri Lanka

Reviewed by: Kihwan Park,

Chung-Ang University,

South Korea

Xuetong Fan,

United States Department of

Agriculture, United States

${ }^{*}$ Correspondence:

Mei-Jun Zhu

meijun.zhu@wsu.edu

tThese authors have contributed equally to this work

Specialty section:

This article was submitted to

Food Microbiology,

a section of the journal

Frontiers in Microbiology

Received: 22 July 2019

Accepted: 14 October 2019 Published: 07 November 2019

Citation:

Hua Z, Korany AM, El-Shinawy SH and Zhu M-J (2019) Comparative Evaluation of Different Sanitizers Against Listeria monocytogenes Biofilms on Major

Food-Contact Surfaces.

Front. Microbiol. 10:2462. doi: 10.3389/fmicb.2019.02462

\author{
Zi Hua ${ }^{1 \dagger}$, Ahmed Mahmoud Korany ${ }^{1,2 \dagger}$, Saadia Helmy El-Shinawy ${ }^{2}$ and Mei-Jun Zhu ${ }^{1 *}$ \\ ${ }^{1}$ School of Food Science, Washington State University, Pullman, WA, United States, ${ }^{2}$ Food Hygiene and Control Department, \\ Faculty of Veterinary Medicine, Beni-Suef University, Beni Suef, Egypt
}

Contaminated food-contact surfaces are recognized as the primary reason for recent $L$. monocytogenes outbreaks in caramel apples and cantaloupes, highlighting the significance of cleaning and sanitizing food-contact surfaces to ensure microbial safety of fresh produce. This study evaluated efficacies of four commonly used chemical sanitizers at practical concentrations against $L$. monocytogenes biofilms on major food-contact surfaces including stainless steel, low-density polyethylene (LDPE), polyvinyl chloride (PVC), polyester (PET), and rubber. In general, efficacies against $L$. monocytogenes biofilms were enhanced by increasing concentrations of quaternary ammonium compound (QAC), chlorine, and chlorine dioxide, or extending treating time from 1 to $5 \mathrm{~min}$. The 5-min treatments of 400 ppm QAC, 5.0 ppm chlorine dioxide, and 200 ppm chlorine reduced 3.0-3.7, 2.4-2.7, and 2.6-3.8 $\log _{10}$ CFU/coupon L. monocytogenes biofilms depending on surfaces. Peroxyacetic acid (PAA) at 160 and 200 ppm showed similar antimicrobial efficacies against biofilms either at 1- or 5-min contact. The 5-min treatment of 200 ppm PAA caused 4.0-4.5 $\log _{10}$ CFU/coupon reduction of $L$. monocytogenes biofilms on tested surfaces. Surface material had more impact on the efficacies of QAC and chlorine, less influence on those of PAA and chlorine dioxide, while organic matter soiling impaired sanitizer efficacies against $L$. monocytogenes biofilms independent of food-contact surfaces. Data from this study provide practical guidance for effective disinfection of foodcontact surfaces in food processing/packing facilities.

Keywords: biofilm, L. monocytogenes, sanitizers, food-contact surfaces, organic matter, peroxyacetic acid

\section{INTRODUCTION}

As a critical foodborne pathogen, Listeria monocytogenes causes approximately 1,600 cases of infection and 260 cases of death annually in the United States (Scallan et al., 2011). It has been implicated in multi-state outbreaks on fresh produce including cantaloupes (CDC, 2012), prepackaged caramel apples (CDC, 2015a), bean sprouts (CDC, 2015b), frozen vegetables (CDC, 2016a), and packaged salads (CDC, 2016b) since 2011. Contaminated food-contact surfaces, packing lines, and environment are incriminated as the primary reasons linked to L. monocytogenes outbreaks in fresh produce (McCollum et al., 2013; Angelo et al., 2017). 
Therefore, it is vital to sanitize food-contact surfaces along produce production lines effectively to ensure microbial safety of fresh produce.

Stainless steel (SS) and plastics are preferably used in the fresh produce industry due to their anti-fouling ability (FDA, 2008). SS, a corrosion-resistant metal, is an excellent material for food processing/packing equipment and extensively used in food industries such as fresh apple packing facilities (Jellesen et al., 2006). A conveyor belt, one of the most prevalent foodcontact surfaces, directly contacts fresh produce and transports it to further processing or packing during post-harvest handling. Polyvinyl chloride (PVC), low-density polyethylene (LDPE), and rubber are FDA-approved food-contact substances that are extensively used as important components of conveyor belts (FDA, 2017). The conveyor belts around the optical sorting lines have been determined to be the major contamination sites in a minimally processed vegetable plant (Meireles et al., 2017). The brush bed, mostly made of polyester (PET), is an important and essential processing tool of the packing lines of fresh apples and other fruits. The contaminated brush-bed spray bar system was implicated in a recent caramel apple $L$. monocytogenes outbreak (Angelo et al., 2017). L. monocytogenes form biofilms on SS, PVC, LDPE, PET, and rubber surfaces (Krysinski et al., 1992; Beresford et al., 2001; Takahashi et al., 2010; Doijad et al., 2015; Papaioannou et al., 2018), exerting enhanced resistances to acid and sanitizer treatments (Ibusquiza et al., 2011; van der Veen and Abee, 2011), which makes routine disinfection in a food processing facility more difficult.

Food-contact surfaces are cleaned and disinfected daily with different chemical sanitizers in fresh produce processing plants and apple packing facilities. Peroxyacetic acid (PAA) is an environment-friendly sanitizer that decomposes and produces no harmful by-product (Dell'Erba et al., 2007). Quaternary ammonium compound (QAC) and chlorine are the most commonly used sanitizers for surface disinfections (Robbins et al., 2005; Olszewska et al., 2016; Dhowlaghar et al., 2018). Chlorine dioxide is considered as an alternative for chlorine due to its high oxidizing capacity ( 2.5 times higher than that of chlorine) (Benarde et al., 1965). The bactericidal effects of the aforementioned sanitizers against L. monocytogenes biofilms on polystyrene surfaces were compromised in the presence of organic matter or when biofilm was aged (Korany et al., 2018). Different food-contact surfaces have unique physicochemical properties and hydrophobicity, which may provide unique harbor sites for L. monocytogenes during sanitizer intervention. Therefore, the objective of this study was to evaluate antimicrobial efficacies of four FDA-approved sanitizers against aged L. monocytogenes biofilms on major food-contact surfaces in the absence or presence of organic matter.

\section{MATERIALS AND METHODS}

\section{L. monocytogenes Strains and Cocktail Preparation}

Listeria monocytogenes strain NRRL B-33069, NRRL B-57618, NRRL B-33006, NRRL B-33466, NRRL B-33071, and NRRL
B-33385 were obtained from USDA-ARS culture collection of National Center (NRRL) for Agricultural Utilization Research (Peoria, IL, United States) and were stored at $-80^{\circ} \mathrm{C}$ in Trypticase Soy Broth with $0.6 \%$ Yeast Extract (TSBYE, Fisher Scientific, Fair Lawn, NJ, United States) and 20\% (v/v) glycerol. Each frozen culture was activated in TSBYE at $35 \pm 2{ }^{\circ} \mathrm{C}$ for $24 \pm 2 \mathrm{~h}$ statically, then sub-cultured in TSBYE for additional $24 \pm 2 \mathrm{~h}$ at $35 \pm 2{ }^{\circ} \mathrm{C}$. The six-strain L. monocytogenes cocktail was prepared by mixing equal volumes of each activated strain, then centrifuged at $8,000 \times g$ for $5 \mathrm{~min}$ at room temperature $\left(22^{\circ} \mathrm{C}\right.$, RT). The resulting pellet was re-suspended in Modified Welshimer's Broth (MWB, HiMedia, West Chester, PA, United States) to have a final population level of $\sim 10^{8} \mathrm{CFU} / \mathrm{ml}$.

\section{Surface Selection, Preparation, and Conditioning}

The SS (AISI 316, No. 4 brushed finish) was obtained from the Washington State University Engineering Shops (Pullman, WA, United States). PVC, LDPE, and PET sheets were purchased from Interstate Plastics (Sacramento, CA, United States), and silicone rubber sheet was purchased from Rubber Sheet Warehouse (Los Angeles, CA, United States). All surface materials were cut into coupons of $15 \mathrm{~mm} \times 7.5 \mathrm{~mm}$ at the Washington State University Engineering Shops.

To clean coupons, the prepared surface coupons were immersed in $100 \%$ methanol (Fisher Scientific) for $1 \mathrm{~h}$, rinsed with sterile water three times, then immersed for $1 \mathrm{~h}$ in $70 \%$ ethanol (Fisher Scientific). The treated coupons were air dried under a biosafety cabinet overnight, which were ready for biofilm growth. To condition surface coupon with organic matter, the above cleaned surface coupons were immersed in 1:10 diluted apple juice or milk for $1 \mathrm{~h}$ at RT (Brown et al., 2014). After removing conditioning solution, coupons were air dried for $1 \mathrm{~h}$ at RT under a biosafety cabinet.

\section{L. monocytogenes Biofilm Formation}

The above prepared coupons were subjected to a 15-min UV treatment in the biosafety hood to surface decontamination before inoculation with $2.0 \mathrm{ml}$ of $L$. monocytogenes cocktail suspension in $\mathrm{MWB}\left(\sim 10^{8} \mathrm{CFU} / \mathrm{ml}\right)$. The inoculated coupons in 24-well plates were incubated statically at RT for 7 days to grow $L$. monocytogenes biofilms without agitation (Abeysundara et al., 2018).

\section{Sanitizer Intervention Against L. monocytogenes Biofilms}

Bioside HS (EnviroTech, Modesto, CA, United States) containing $15 \%$ PAA was used to prepare 160 and 200 ppm PAA solutions using sterile water. STOPIT (Pace International, Wapato, WA, United States) was diluted with sterile water to prepare 200 and 400 ppm QAC solutions. Chlorine solutions at 100 and 200 ppm were made from Accu-Tab (Pace International, Wapato, WA, United States), while 2.5 and $5.0 \mathrm{ppm}$ chlorine dioxide solutions were generated on-site using chlorine dioxide generator donated by Pace International (Wapato, WA, United States). Concentration of PAA was verified using a AquaPhoenix Preacetic Acid test kit (Hanover, PA, United States), levels of 
QAC and chlorine were confirmed by the QAC and Chlorine test kits from LaMotte (Chestertown, MD, United States), and the concentration of chlorine dioxide solutions were measured by a HACH Chlorine Dioxide test kit (Loveland, CO, United States).

To evaluate the antimicrobial efficacy of sanitizers, 7-day-old L. monocytogenes biofilms on each surface coupon were washed with $2.0 \mathrm{ml}$ of sterile phosphate buffered saline (PBS) three times and then immersed in $2.0 \mathrm{ml}$ of each sanitizer solution for 1 or $5 \mathrm{~min}$ at RT. Coupons were first rinsed with $2.0 \mathrm{ml}$ of Dey-Engley Neutralizing Broth (Oxoid, United States), then $2.0 \mathrm{ml}$ sterile PBS immediately after sanitizer treatment. Four replicates were used for each surface material and sanitizer treatment, and triple independent experiments were conducted for each treatment combination.

\section{Biofilm Detachment and Enumeration}

To detach and enumerate the L. monocytogenes cells in biofilm on the above treated coupons, the coupon in the respective well was transferred to $2-\mathrm{ml}$ microtube containing $1.0 \mathrm{ml}$ of sterile PBS and $3 \sim 4$ glass beads. The tubes containing coupons were vigorously vortexed for $2 \mathrm{~min}$ using a benchtop mixer at the maximal speed. The detached bacterial suspension was 10 -fold serially diluted with sterile PBS, and appropriate dilution was plated on TSAYE plates in duplicate. The plates were incubated at $35 \pm 2{ }^{\circ} \mathrm{C}$ for $48 \mathrm{~h}$ before enumeration.

\section{Statistical Analysis}

Data were analyzed by uncorrected Fisher's Least Significant Difference (LSD) to determine significant difference among groups at $p \leq 0.05$ using Prism (Version 7.0, San Diego, CA, United States).
Each experiment was repeated three times independently. Data were presented as an average from three independent studies and mean \pm standard error mean (SEM) was reported.

\section{RESULTS}

\section{Efficacy of Quaternary Ammonium Compound Against L. monocytogenes Biofilms on Food-Contact Surfaces}

In general, increasing the QAC concentration from 200 to 400 ppm improved its efficacy against L. monocytogenes biofilms on different food-contact surfaces except LDPE surface for both 1- and 5-min exposures (Figure 1). A 5 -min exposure of QAC at 200 or 400 ppm showed a similar efficacy against L. monocytogenes biofilms on SS coupons (Figure 1A). Except for rubber surface, the efficacy of QAC against L. monocytogenes biofilms on different surfaces was enhanced when exposure time increased from 1 to $5 \mathrm{~min}$ (Figure 1). Among all surfaces, QAC at $5 \mathrm{~min}$ exposure was the most effective against $L$. monocytogenes biofilms on SS (Figure 1A), least effective against L. monocytogenes biofilms on rubber (Figure 1E), while exhibiting a comparable efficacy against L. monocytogenes biofilms on LDPE and PET (Figures 1B-D). For L. monocytogenes biofilms on PVC surface, the 5-min exposure of 400 ppm QAC showed a similar efficacy as those of LDPE and PET; however, $200 \mathrm{ppm}$ QAC for 5 min of exposure was less effective on PVC surface than those of LDPE and PET (Figures 1B-D). QAC at the FDA-approved concentration of $400 \mathrm{ppm}$ for 5 min caused $3.7,3.2,3.7,3.6$, and $3.0 \log _{10} \mathrm{CFU} /$ coupon reductions of L. monocytogenes biofilms on SS, LDPE, PVC, PET, and rubber surface, respectively (Figure 1).

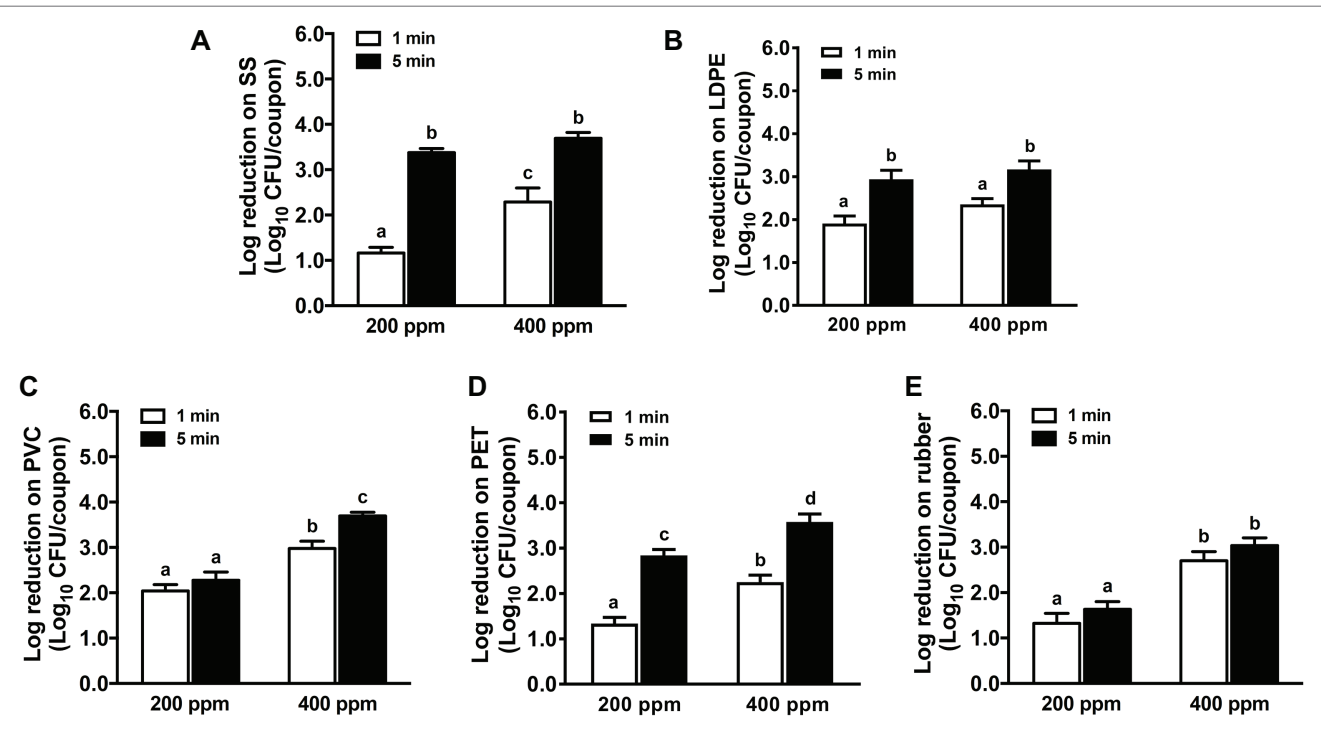

FIGURE 1 | Antimicrobial efficacy of quaternary ammonium compound (QAC) against $L$. monocytogenes biofilms on food-contact surfaces. (A) Stainless steel (SS); (B) low-density polyethylene (LDPE); (C) polyvinyl chloride (PVC); (D) polyester (PET); (E) rubber. The 7-day-old biofilms on different surface coupons $\left(15 \mathrm{~mm} \times 7.5 \mathrm{~mm}\right.$ ) were treated with 200 or $400 \mathrm{ppm}$ QAC for 1 or $5 \mathrm{~min}$ at $22^{\circ} \mathrm{C}$. The surviving bacteria were shown as means $\pm \mathrm{SEMs}, n=3$. ${ }^{\mathrm{a}-\mathrm{d} B a r s}$ topped with the different letters are significantly different at $p \leq 0.05$. 


\section{Efficacies of Chlorine and Chlorine Dioxide Against $L$. monocytogenes Biofilms on Food-Contact Surfaces}

Chlorine dioxide solution at $2.5 \mathrm{ppm}$ exhibited a limited efficacy against $L$. monocytogenes biofilms on all surfaces tested; 1-min treatments only reduced $\sim 1.1,0.6,0.9,1.1$, and $0.9 \log _{10} \mathrm{CFU} /$ coupon L. monocytogenes biofilms on SS, LDPE, PVC, PET, and rubber surfaces, respectively (Figure 2). Though the efficacy of chlorine dioxide was enhanced with increased concentration and contact time, it displayed limited potency to inactivate $L$. monocytogenes biofilms on food-contact surfaces. A 5-min treatment of $5.0 \mathrm{ppm}$ chlorine dioxide caused similar bactericidal efficacy against L. monocytogenes biofilms on all surfaces with 2.4-2.7 $\log _{10} \mathrm{CFU} /$ coupon reductions (Figure 2 ).

The efficacy of chlorine against $L$. monocytogenes biofilms on the tested surfaces was enhanced at increased concentration and extended contact time except LDPE surface (Figure 3). A 1-min treatment of $100 \mathrm{ppm}$ chlorine showed a similar efficacy against L. monocytogenes biofilms as 1-min exposure of 200 ppm QAC (Figure 1) and was more effective than 1-min treatment of $2.5 \mathrm{ppm}$ chlorine dioxide (Figure 2), causing 1.0-2.0 $\log _{10} \mathrm{CFU} / \mathrm{coupon}$ reductions of biofilms on all surfaces tested. Chlorine at $200 \mathrm{ppm}$ for 5.0-min exposure caused 3.8, 2.7, 3.3, 3.6, and $3.0 \log _{10} \mathrm{CFU} /$ coupon reductions of $L$. monocytogenes biofilms on SS, LDPE, PVC, PET, and rubber surfaces, respectively (Figure 3 ).

\section{Efficacy of Peroxyacetic Acid Against L. monocytogenes Biofilms on Food-Contact Surfaces}

Among all selected sanitizers, PAA was the most effective against L. monocytogenes biofilms on all food-contact surfaces
(Figure 4). One min treatment of 160 ppm PAA reduced $\sim 4.3,3.5,3.8,4.1$, and $3.7 \log _{10} \mathrm{CFU} /$ coupon L. monocytogenes biofilms on SS, LDPE, PVC, PET, and rubber surfaces, respectively (Figure 4). In general, the bactericidal effects of PAA against L. monocytogenes biofilms on all surfaces was not improved when the PAA concentration increased from 160 to $200 \mathrm{ppm}$ or when the treatment time increased from 1 to $5 \mathrm{~min}$ (Figure 4). The 5-min treatment of 200 ppm PAA caused 4.5, 4.0, 4.4, 4.3, and $4.4 \log _{10} \mathrm{CFU} /$ coupon reductions of $L$. monocytogenes biofilms on SS, PET, PVC, LDPE, and rubber, respectively (Figure 4).

\section{Effects of Organic Matter on Sanitizer's Efficacy}

The anti-Listeria efficacies of all sanitizers were compromised by organic matter regardless of surfaces tested; food residues from apple juice or milk comparably impacted QAC efficacy (Figure 5). Soiling has a greater influence on the antimicrobial efficacy of QAC against biofilms on SS and rubber than those on LDPE, PET, and PVC (Figure 5A). Among all tested surfaces, the anti-Listeria efficacy of chlorine on SS is the most impacted by organic matter. Chlorine at $200 \mathrm{ppm}$ and 5-min contact time showed a similar anti-Listeria efficacy on soiled SS, LDPE and rubber surfaces regardless of organic matter type (Figure 5B). The bactericidal effect of chlorine dioxide against $L$. monocytogenes biofilms was compromised by organic matter regardless of surface materials or food residue source. Chlorine dioxide at $5.0 \mathrm{ppm}$ for $5 \mathrm{~min}$ caused 1.0-2.0 $\log _{10} \mathrm{CFU} /$ coupon reduction depending on surface material (Figure 5C). Though the PAA efficacy against L. monocytogenes biofilms on all surfaces was impaired by organic soiling as much as other sanitizers, it was still the most effective sanitizer, which caused 3.0-3.7 $\log _{10}$ CFU/coupon reductions of L. monocytogenes biofilms on different surfaces (Figure 5D).
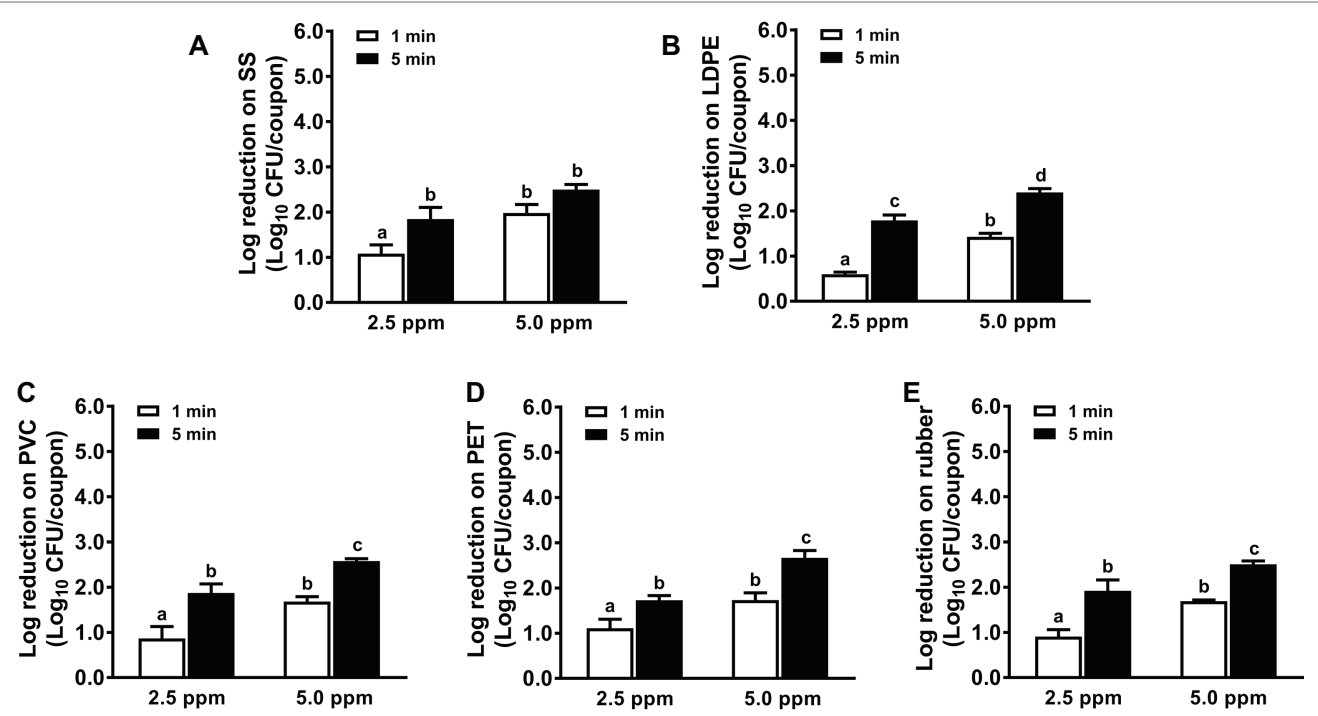

FIGURE 2 | Antimicrobial efficacy of chlorine dioxide against L. monocytogenes biofilms on food-contact surfaces. (A) Stainless steel (SS); (B) low-density polyethylene (LDPE); (C) polyvinyl chloride (PVC); (D) polyester (PET); (E) rubber. The 7-day-old biofilms on different surface coupons (15 mm $\times 7.5 \mathrm{~mm})$ were treated with 2.5 or $5.0 \mathrm{ppm}$ chlorine dioxide solution for 1 or $5 \mathrm{~min}$ at $22^{\circ} \mathrm{C}$. The remaining bacteria post-sanitizer treatment were shown as means $\pm \mathrm{SEMs}, n=3$. a-dBars topped with the different letters are significantly different at $p \leq 0.05$. 

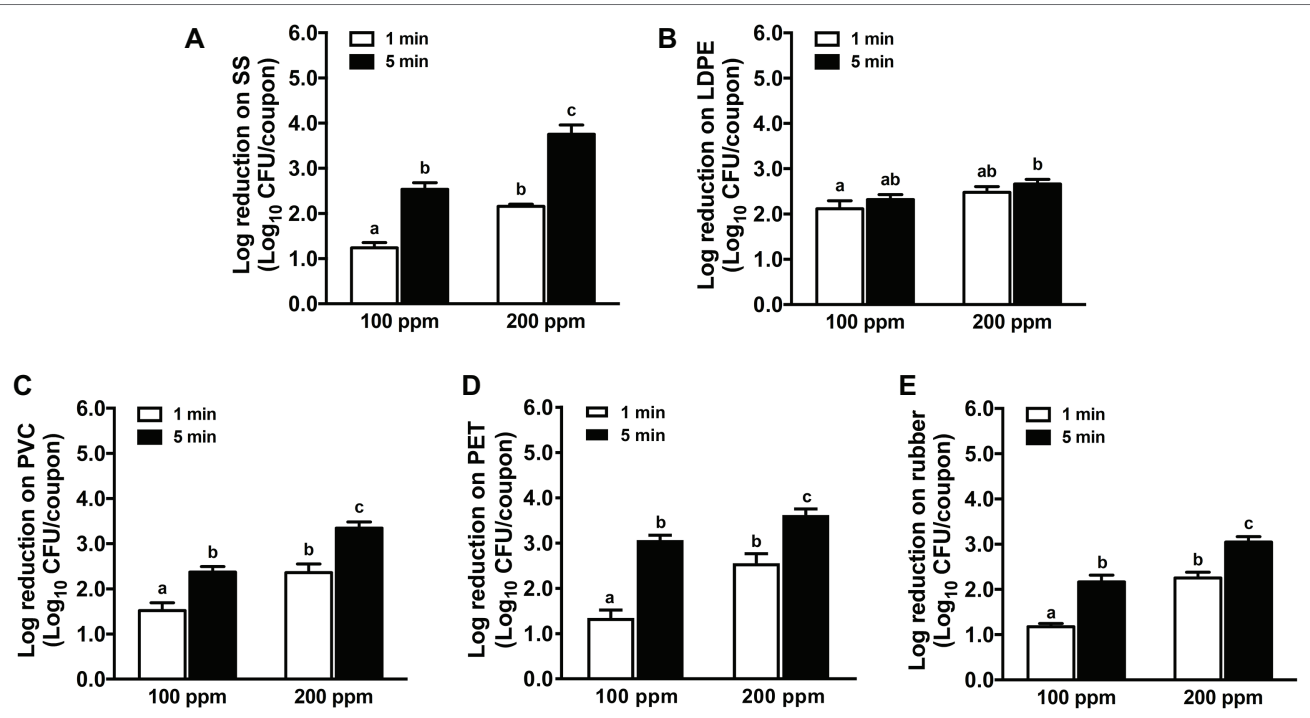

FIGURE 3 | Antimicrobial efficacy of chlorine against L. monocytogenes biofilms on food-contact surfaces. (A) Stainless steel (SS); (B) low-density polyethylene (LDPE); (C) polyvinyl chloride (PVC); (D) polyester (PET); (E) rubber. The 7-day-old biofilms on different surface coupons (15 mm $\times 7.5 \mathrm{~mm}$ ) were treated with 100 or $200 \mathrm{ppm}$ chlorine solution for 1 or $5 \mathrm{~min}$ at $22^{\circ} \mathrm{C}$. The survivors post-chlorine treatment were enumerated and shown as means \pm SEMs, $n=3$. ${ }^{a-c} B a r s$ topped with the different letters are significantly different at $p \leq 0.05$.
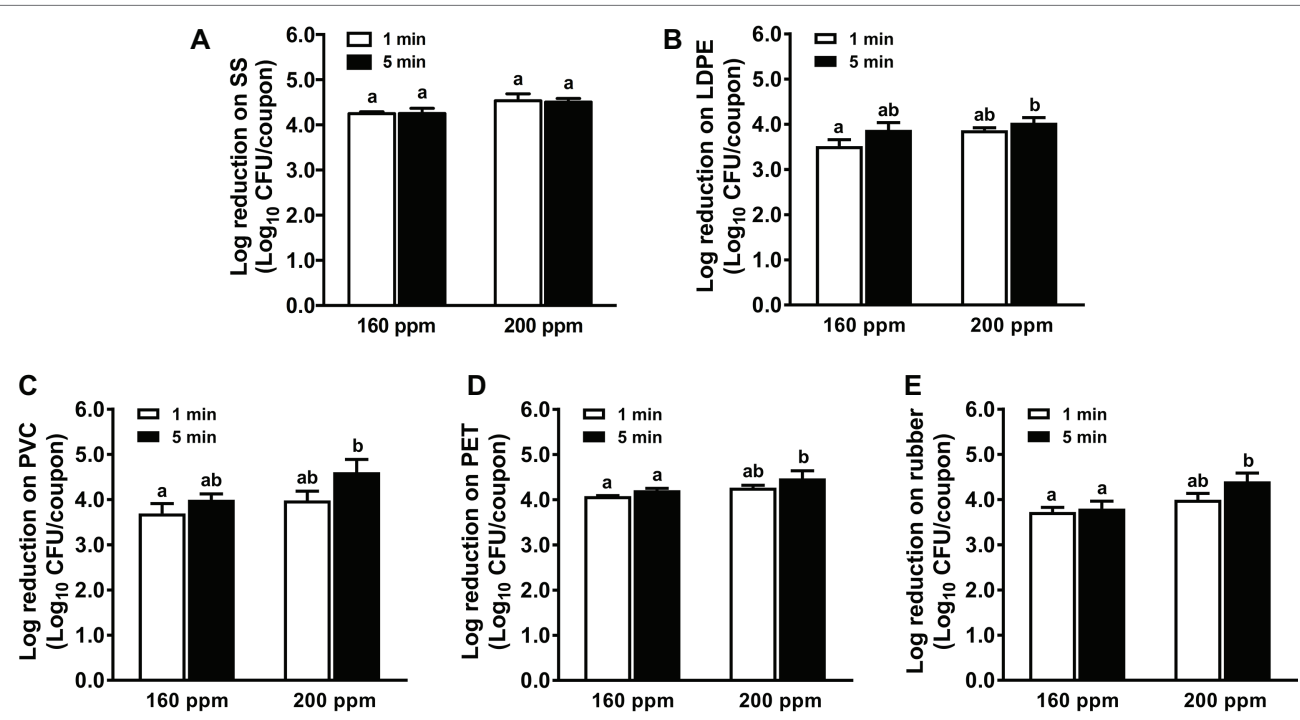

FIGURE 4 | Antimicrobial efficacy of peroxyacetic acid (PAA) against L. monocytogenes biofilms on food-contact surfaces. (A) Stainless steel (SS); (B) low-density polyethylene (LDPE); (C) polyvinyl chloride (PVC); (D) polyester (PET); (E) rubber. The 7-day-old biofilms on different surface coupons (15 mm $\times 7.5 \mathrm{~mm}$ ) were treated with 160 or $200 \mathrm{ppm}$ PAA for 1 or 5 min at $22^{\circ} \mathrm{C}$. The surviving bacteria were shown as means \pm SEMs, $n=3$, a,bBars topped with the different letters are significantly different at $p \leq 0.05$.

\section{DISCUSSION}

\section{The Effect of Concentration, Contacting Time of Sanitizers on Inactivation of \\ L. monocytogenes}

The concentrations of QAC, chlorine dioxide, chlorine and PAA against $L$. monocytogenes biofilms on common food-contact surfaces were selected complying with FDA regulation (FDA, 2017). The 200 ppm QAC, 2.5 ppm chlorine dioxide, or 100 ppm chlorine interventions showed limited efficacies against aged $L$. monocytogenes biofilms on different food-contact surfaces, but their efficacies were enhanced with increased concentrations, which was consistent with our previous findings on polystyrene surface (Korany et al., 2018) and other studies on SS surface (Robbins et al., 2005; Trinetta et al., 2012; Dhowlaghar et al., 2018). The antimicrobial efficacies of QAC, chlorine dioxide, and chlorine at selected concentrations were improved when increasing contact time from 1 to $5 \mathrm{~min}$, which is supported by a recent 


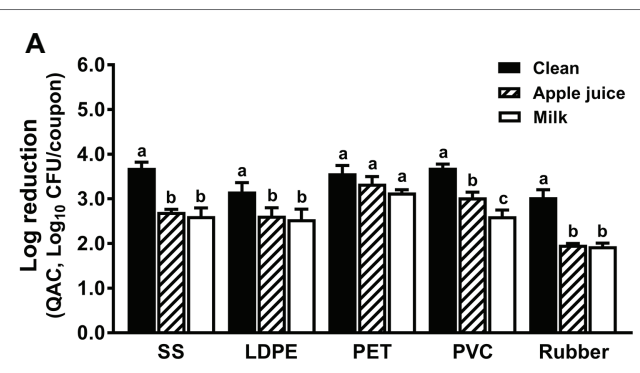

C

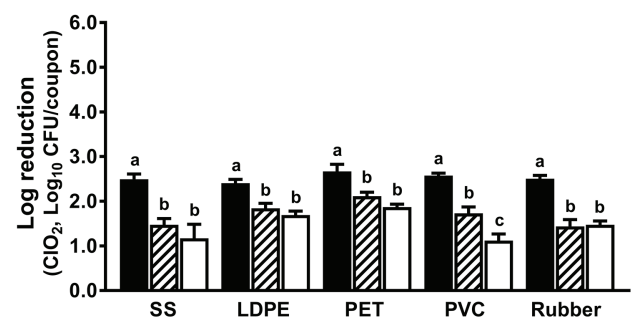

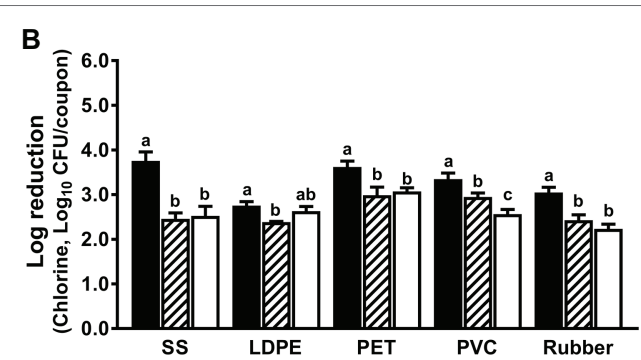

D

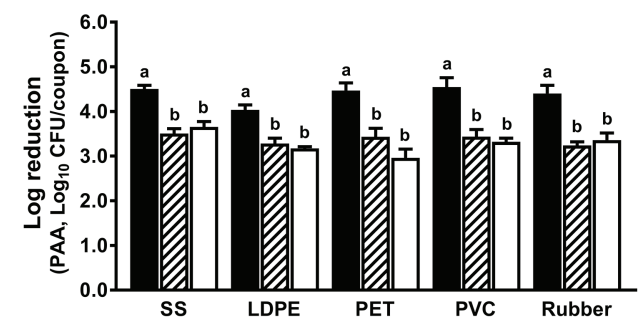

FIGURE 5 | Efficacy of four commonly used sanitizers against L. monocytogenes biofilms on food-contact surfaces conditioned with organic matters. (A) Quaternary ammonium compound (QAC, 400 ppm); (B) chlorine (200 ppm); (C) chlorine dioxide $\left(\mathrm{ClO}_{2}, 5.0\right.$ ppm); (D) peroxyacetic acid (PAA, 200 ppm); stainless steel (SS); low-density polyethylene (LDPE); polyester (PET); polyvinyl chloride (PVC). Apple juice: food-contact surfaces were conditioned with apple juice; milk: food-contact surfaces were conditioned with milk. The 7-day-old biofilms on different surface coupons $(15 \mathrm{~mm} \times 7.5 \mathrm{~mm})$ were treated with the respective sanitizers for $5 \mathrm{~min}$, then survivors were enumerated and shown as means \pm SEMs, $n=3 .{ }^{a-c}$ Bars topped with the different letters are not significantly different at $p \leq 0.05$.

report of QAC and chlorine against $L$. monocytogenes biofilms on SS surface (Dhowlaghar et al., 2018). Similarly, the efficacy of chlorine dioxide in aqueous and gaseous phase against $L$. monocytogenes biofilms on food contact surfaces increased with extended contact time (Vaid et al., 2010; Trinetta et al., 2012; Park and Kang, 2017). Increasing PAA concentration from 160 to $200 \mathrm{ppm}$ or extending the contacting time from 1 to $5 \mathrm{~min}$ at selected concentration did not improve its efficacy in general. A similar result was obtained for L. monocytogenes biofilms on polystyrene surfaces (Korany et al., 2018). Compared with QAC, chlorine, and chlorine dioxide, PAA tested in the present study was the most effective sanitizer against aged L. monocytogenes biofilms on all surfaces, which was consistent with findings on polystyrene (Korany et al., 2018), SS (Dhowlaghar et al., 2018), and PVC (Berrang et al., 2008). It could be due to its high reactivity, oxidizing capacity, decomposition rate, and low molecular weight, which together allow PAA to penetrate biofilm matrix, thus accomplishing bactericidal activity (Ibusquiza et al., 2011).

\section{Effects of Surface Materials on Efficacy of Different Sanitizers Against \\ L. monocytogenes}

The efficacies of sanitizers against aged L. monocytogenes biofilms varied on different surfaces. The 1-min treatment of QAC or chlorine at selected concentrations caused comparative efficacies against L. monocytogenes biofilms on SS, PET, and rubber, which is supported by a previous report on polystyrene surface (Korany et al., 2018). Compared with rubber and LDPE, $400 \mathrm{ppm}$ QAC and $200 \mathrm{ppm}$ chlorine at 5-min exposure were more effective against $L$. monocytogenes biofilms on SS and other surfaces. In support of our finding, L. monocytogenes on rubber surface was more difficult to remove by chlorine, QAC, and chlorine dioxide than that on SS surface (Ronner and Wong, 1993; Park and Kang, 2017). Different from QAC and chlorine, the anti-Listeria effects of PAA and chlorine dioxide were minimally influenced by surface material at different concentration and time combinations. Regardless of surfaces, chlorine dioxide at $5.0 \mathrm{ppm}$ showed a $2.5 \mathrm{log}$ reduction after 5 -min treatment, which is a very limited efficacy in contrast to 4.0 or more reduction caused by $200 \mathrm{ppm}$ PAA at $5-\mathrm{min}$ contact. Similar to our results, the aerosolized PAA exhibited similar antimicrobial efficacy against $L$. monocytogenes biofilms on SS and PVC surfaces, though the efficacy was lower than our finding (Park et al., 2012). Each type of surface material has different topography and roughness that provide unique microcracks/harbor sites for L. monocytogenes and protect the entrapped cells from antimicrobial agents (Chaturongkasumrit et al., 2011; Schlisselberg and Yaron, 2013), which might explain the difference in efficacy against biofilms on different surfaces. In support, $20 \mathrm{ppm}$ gaseous chlorine dioxide was more effective against attached L. monocytogenes on glossy SS than coarse SS, and Salmonella biofilms on smooth SS were more susceptible to $50 \mathrm{ppm}$ chlorine treatment than those on a rough surface (Schlisselberg and Yaron, 2013). Surface materials with different hydrophobicity and hydration levels lead to various sanitizing efficacy; hydrophobic surface was more difficult to clean than hydrophilic surface (Park and Kang, 2017).

\section{The Antimicrobial Efficacy of Sanitizers in the Presence of Organic Matter}

Food residues established on food-contact surfaces alter the physicochemical property of these surfaces and impact sanitizer 
efficacy (Abban et al., 2012; Brown et al., 2014). The present study indicated that organic soiling, regardless of sources, impaired efficacies of all sanitizers against biofilms on all foodcontact surfaces, which is consistent with the finding on polystyrene surface (Korany et al., 2018). In agreement with our findings, protein and fat residues on SS reduced the efficacies of chlorine dioxide (Vandekinderen et al., 2009), hydrogen peroxide (Moretro et al., 2019), acidic electrolyzed water and sodium hypochlorite (Ayebah et al., 2006), QAC, chlorine, and PAA (Aarnisalo et al., 2000; Somers and Wong, 2004; Kuda et al., 2008) against L. monocytogenes biofilms. Besides attracting bacterial cells as an adhesive layer, protein coating reduced water contact angle, leading to decreased hydrophobicity of food-contact surface (Abban et al., 2012; Park and Kang, 2017). In addition, sanitizers may have difficulty reaching bacterial cells due to the physical and chemical barriers built up by exopolysaccharide substance of biofilm matrix together with food residues (Fernandes et al., 2015).

\section{CONCLUSION}

The type of surface material has more dramatic effects on anti-Listeria efficacy of QAC and chlorine than those treated with chlorine dioxide and PAA. Food residue soiling, regardless of sources, reduced anti-Listeria efficacies of all sanitizers against biofilms on surfaces in general. Among all sanitizers, PAA was the most effective sanitizer against $L$. monocytogenes biofilms on different surfaces. A 5-min treatment of 200 ppm PAA resulted in 3.0-3.7 $\log _{10}$ reductions of aged multi-strain $L$. monocytogenes biofilms on major food contact surfaces in the presence of organic matter. Data once again highlight the importance of thorough cleaning of food-contact surfaces prior

\section{REFERENCES}

Aarnisalo, K., Salo, S., Miettinen, H., Suihko, M. L., Wirtanen, G., Autio, T., et al. (2000). Bactericidal efficiencies of commercial disinfectants against Listeria monocytogenes on surfaces. J. Food Saf. 20, 237-250. doi: 10.1111/ j.1745-4565.2000.tb00302.x

Abban, S., Jakobsen, M., and Jespersen, L. (2012). Attachment behaviour of Escherichia coli K12 and Salmonella typhimurium P6 on food contact surfaces for food transportation. Food Microbiol. 31, 139-147. doi: 10.1016/j.fm.2012.04.003

Abeysundara, P. D. A., Dhowlaghar, N., Nannapaneni, R., Schilling, M. W., Mahmoud, B., Sharma, C. S., et al. (2018). Salmonella enterica growth and biofilm formation in flesh and peel cantaloupe extracts on four food-contact surfaces. Int. J. Food Microbiol. 280, 17-26. doi: 10.1016/j.ijfoodmicro.2018.04.042

Angelo, K. M., Conrad, A. R., Saupe, A., Dragoo, H., West, N., Sorenson, A., et al. (2017). Multistate outbreak of Listeria monocytogenes infections linked to whole apples used in commercially produced, prepackaged caramel apples: United States, 2014-2015. Epidemiol. Infect. 145, 848-856. doi: 10.1017/S0950268816003083

Ayebah, B., Hung, Y. C., Kim, C., and Frank, J. F. (2006). Efficacy of electrolyzed water in the inactivation of planktonic and biofilm Listeria monocytogenes in the presence of organic matter. J. Food Prot. 69, 2143-2150. doi: 10.4315/ 0362-028X-69.9.2143

Benarde, M. A., Israel, B. M., Olivieri, V. P., and Granstrom, M. L. (1965). Efficiency of chlorine dioxide as a bactericide. Appl. Environ. Microbiol. 13, 776-780.

Beresford, M. R., Andrew, P. W., and Shama, G. (2001). Listeria monocytogenes adheres to many materials found in food-processing environments. J. Appl. Microbiol. 90, 1000-1005. doi: 10.1046/j.1365-2672.2001.01330.x to sanitizer interventions and provide useful information for food industries in selecting appropriate sanitizers for foodcontact surfaces' decontamination.

\section{DATA AVAILABILITY STATEMENT}

The datasets generated for this study are available on request to the corresponding author.

\section{AUTHOR CONTRIBUTIONS}

$\mathrm{ZH}$ and $\mathrm{AK}$ conducted the experiments. $\mathrm{ZH}$ wrote the manuscript. $\mathrm{M}-\mathrm{JZ}$ designed the study. M-JZ and SE-S revised the manuscript.

\section{FUNDING}

This study was supported by Washington Tree Fruit Research Commission.

\section{ACKNOWLEDGMENTS}

We acknowledge Pace International Inc. for their generous donations of Accu-Tab, Bioside HS, STOP-IT, and the Chlorine Dioxide Generator. We would like to express our gratitude to Dr. Ines Hanrahan at Washington Tree Fruit Research for her input from a practical industry perspective. We thank Mrs. Tonia Green for her assistance in preparation of experimental materials and Mr. Mike Taylor for his critical reading of the manuscript.

Berrang, M. E., Frank, J. F., and Meinersmann, R. J. (2008). Effect of chemical sanitizers with and without ultrasonication on Listeria monocytogenes as a biofilm within polyvinyl chloride drain pipes. J. Food Prot. 71, 66-69. doi: 10.4315/0362-028X-71.1.66

Brown, H. L., Reuter, M., Salt, L. J., Cross, K. L., Betts, R. P., and van Vliet, A. H. M. (2014). Chicken juice enhances surface attachment and biofilm formation of Campylobacter jejuni. Appl. Environ. Microbiol. 80, 7053-7060. doi: 10.1128/AEM.02614-14

CDC (2012). Multistate outbreak of listeriosis linked to whole cantaloupes from Jensen farms, Colorado (final update). Available at: https://www.cdc.gov/ listeria/outbreaks/cantaloupes-jensen-farms/index.html (Accessed July 20, 2019).

CDC (2015a). Multistate outbreak of listeriosis linked to commercially produced, prepackaged caramel apples made from Bidart bros, apples (final update). Available at: https://www.cdc.gov/listeria/outbreaks/caramel-apples-12-14/index. html (Accessed July 20, 2019).

CDC (2015b). Wholesome soy products, Inc. sprouts and investigation of human listeriosis cases (final update). Available at: https://www.cdc.gov/listeria/ outbreaks/bean-sprouts-11-14/index.html (Accessed July 20, 2019).

CDC (2016a). Multistate outbreak of listeriosis linked to frozen vegetables (final update). Available at: https://www.cdc.gov/listeria/outbreaks/frozenvegetables-05-16/index.html (Accessed July 20, 2019).

CDC (2016b). Multistate outbreak of listeriosis linked to packaged salads produced at Springfield, Ohio dole processing facility (final update). Available at: https://www.cdc.gov/listeria/outbreaks/bagged-salads-01-16/index.html (Accessed July 20, 2019).

Chaturongkasumrit, Y., Takahashi, H., Keeratipibul, S., Kuda, T., and Kimura, B. (2011). The effect of polyesterurethane belt surface roughness on Listeria 
monocytogenes biofilm formation and its cleaning efficiency. Food Control 22, 1893-1899. doi: 10.1016/j.foodcont.2011.04.032

Dell'Erba, A., Falsanisi, D., Liberti, L., Notarnicola, M., and Santoroa, D. (2007). Disinfection by-products formation during wastewater disinfection with peracetic acid. Desalination 215, 177-186. doi: 10.1016/j.desal.2006.08.021

Dhowlaghar, N., Abeysundara, P. D., Nannapaneni, R., Schilling, M. W., Chang, S., Cheng, W. H., et al. (2018). Growth and biofilm formation by Listeria monocytogenes in catfish mucus extract on four food contact surfaces at 22 and $10^{\circ} \mathrm{C}$ and their reduction by commercial disinfectants. J. Food Prot. 81, 59-67. doi: 10.4315/0362-028X.JFP-17-103

Doijad, S. P., Barbuddhe, S. B., Garg, S., Poharkar, K. V., Kalorey, D. R., Kurkure, N. V., et al. (2015). Biofilm-forming abilities of Listeria monocytogenes serotypes isolated from different sources. PLoS One 10:e0137046. doi: 10.1371/ journal.pone.0137046

FDA (2008). Guidance for industry: guide to minimize microbial food safety hazards of fresh-cut fruits and vegetables. Available at: https://www.fda.gov/ food/guidanceregulation/ucm064458.htm (Accessed July 20, 2019).

FDA (2017). CFR-code of federal regulations title 21. Available at: https://www. accessdata.fda.gov/scripts/cdrh/cfdocs/cfcfr/cfrsearch.cfm (Accessed July 20, 2019).

Fernandes, M. D., Kabuki, D. Y., and Kuaye, A. Y. (2015). Behavior of Listeria monocytogenes in a multi-species biofilm with Enterococcus faecalis and Enterococcus faecium and control through sanitation procedures. Int. J. Food Microbiol. 200, 5-12. doi: 10.1016/j.ijfoodmicro.2015.01.003

Ibusquiza, P. S., Herrera, J. J. R., and Cabo, M. L. (2011). Resistance to benzalkonium chloride, peracetic acid and nisin during formation of mature biofilms by Listeria monocytogenes. Food Microbiol. 28, 418-425. doi: 10.1016/j. fm.2010.09.014

Jellesen, M. S., Rasmussen, A. A., and Hilbert, L. R. (2006). A review of metal release in the food industry. Mater. Corros. 57, 387-393. doi: 10.1002/ maco. 200503953

Korany, A. M., Hua, Z., Green, T., Hanrahan, I., El-Shinawy, S. H., El-Kholy, A., et al. (2018). Efficacy of ozonated water, chlorine, chlorine dioxide, quaternary ammonium compounds and peroxyacetic acid against Listeria monocytogenes biofilm on polystyrene surfaces. Front. Microbiol. 9:2296. doi: 10.3389/fmicb.2018.02296

Krysinski, E., Brown, L., and Marchisello, T. (1992). Effect of cleaners and sanitizers on Listeria monocytogenes attached to product contact surfaces. J. Food Prot. 55, 246-251. doi: 10.4315/0362-028X-55.4.246

Kuda, T., Yano, T., and Kuda, M. T. (2008). Resistances to benzalkonium chloride of bacteria dried with food elements on stainless steel surface. LWT Food Sci. Technol. 41, 988-993. doi: 10.1016/j.lwt.2007.06.016

McCollum, J. T., Cronquist, A. B., Silk, B. J., Jackson, K. A., O’Connor, K. A., Cosgrove, S., et al. (2013). Multistate outbreak of listeriosis associated with cantaloupe. New Engl. J. Med. 369, 944-953. doi: 10.1056/NEJMoa1215837

Meireles, A., Fulgencio, R., Machado, I., Mergulhao, F., Melo, L., and Simoes, M. (2017). Characterization of the heterotrophic bacteria from a minimally processed vegetables plant. LWT Food Sci. Technol. 85, 293-300. doi: 10.1016/j. lwt.2017.01.038

Moretro, T., Fanebust, H., Fagerlund, A., and Langsrud, S. (2019). Whole room disinfection with hydrogen peroxide mist to control Listeria monocytogenes in food industry related environments. Int. J. Food Microbiol. 292, 118-125. doi: 10.1016/j.ijfoodmicro.2018.12.015

Olszewska, M. A., Zhao, T., and Doyle, M. P. (2016). Inactivation and induction of sublethal injury of Listeria monocytogenes in biofilm treated with various sanitizers. Food Control 70, 371-379. doi: 10.1016/j.foodcont.2016.06.015

Papaioannou, E., Giaouris, E. D., Berillis, P., and Boziaris, I. S. (2018). Dynamics of biofilm formation by Listeria monocytogenes on stainless steel under mono-species and mixed-culture simulated fish processing conditions and chemical disinfection challenges. Int. J. Food Microbiol. 267, 9-19. doi: 10.1016/j.ijfoodmicro.2017.12.020

Park, S. H., Cheon, H. L., Park, K. H., Chung, M. S., Choi, S. H., Ryu, S., et al. (2012). Inactivation of biofilm cells of foodborne pathogen by aerosolized sanitizers. Int. J. Food Microbiol. 154, 130-134. doi: 10.1016/j. ijfoodmicro.2011.12.018

Park, S. H., and Kang, D. H. (2017). Influence of surface properties of produce and food contact surfaces on the efficacy of chlorine dioxide gas for the inactivation of foodborne pathogens. Food Control 81, 88-95. doi: 10.1016/j. foodcont.2017.05.015

Robbins, J. B., Fisher, C. W., Moltz, A. G., and Martin, S. E. (2005). Elimination of Listeria monocytogenes biofilms by ozone, chlorine, and hydrogen peroxide. J. Food Prot. 68, 494-498. doi: 10.4315/0362-028X-68.3.494

Ronner, A. B., and Wong, A. C. L. (1993). Biofilm development and sanitizer inactivation of Listeria monocytogenes and Salmonella typhimurium on stainless steel and Buna-N rubber. J. Food Prot. 56, 750-758. doi: 10.4315/ 0362-028X-56.9.750

Scallan, E., Hoekstra, R. M., Angulo, F. J., Tauxe, R. V., Widdowson, M. A., Roy, S. L., et al. (2011). Foodborne illness acquired in the United Statesmajor pathogens. Emerg. Infect. Dis. 17, 7-15. doi: 10.3201/eid1701.P11101

Schlisselberg, D. B., and Yaron, S. (2013). The effects of stainless steel finish on Salmonella typhimurium attachment, biofilm formation and sensitivity to chlorine. Food Microbiol. 35, 65-72. doi: 10.1016/j.fm.2013.02.005

Somers, E. B., and Wong, A. C. L. (2004). Efficacy of two cleaning and sanitizing combinations on Listeria monocytogenes biofilms formed at low temperature on a variety of materials in the presence of ready-to-eat meat residue. J. Food Prot. 67, 2218-2229. doi: 10.4315/0362-028X-67.10.2218

Takahashi, H., Suda, T., Tanaka, Y., and Kimura, B. (2010). Cellular hydrophobicity of Listeria monocytogenes involves initial attachment and biofilm formation on the surface of polyvinyl chloride. Lett. Appl. Microbiol. 50, 618-625. doi: $10.1111 /$ j.1472-765X.2010.02842.x

Trinetta, V., Vaid, R., Xu, Q., Linton, R., and Morgan, M. (2012). Inactivation of Listeria monocytogenes on ready-to-eat food processing equipment by chlorine dioxide gas. Food Control 26, 357-362. doi: 10.1016/j.foodcont.2012.02.008

Vaid, R., Linton, R. H., and Morgan, M. T. (2010). Comparison of inactivation of Listeria monocytogenes within a biofilm matrix using chlorine dioxide gas, aqueous chlorine dioxide and sodium hypochlorite treatments. Food Microbiol. 27, 979-984. doi: 10.1016/j.fm.2010.05.024

van der Veen, S., and Abee, T. (2011). Mixed species biofilms of Listeria monocytogenes and Lactobacillus plantarum show enhanced resistance to benzalkonium chloride and peracetic acid. Int. J. Food Microbiol. 144, 421-431. doi: 10.1016/j.ijfoodmicro.2010.10.029

Vandekinderen, I., Devlieghere, F., Van Camp, J., Kerkaert, B., Cucu, T., Ragaert, P., et al. (2009). Effects of food composition on the inactivation of foodborne microorganisms by chlorine dioxide. Int. J. Food Microbiol. 131, 138-144. doi: 10.1016/j.ijfoodmicro.2009.02.004

Conflict of Interest: The authors declare that the research was conducted in the absence of any commercial or financial relationships that could be construed as a potential conflict of interest.

Copyright (c) 2019 Hua, Korany, El-Shinawy and Zhu. This is an open-access article distributed under the terms of the Creative Commons Attribution License (CC BY). The use, distribution or reproduction in other forums is permitted, provided the original author(s) and the copyright owner(s) are credited and that the original publication in this journal is cited, in accordance with accepted academic practice. No use, distribution or reproduction is permitted which does not comply with these terms. 